\title{
The Modification Effect of Piston Crown on Four Stroke One Cylinder Diesel Engine using Biodiesel B30 on Noise Based on Simulation.
}

\author{
Beny Cahyono ${ }^{1}$, Adhi Iswantoro ${ }^{2}$, Ilham Rezandhi Akbar $^{3}$ \\ (Received: 22 August 2020 / Revised: 15 December 2020 / Accepted: 20 December 2020)
}

\begin{abstract}
— piston is one of the important parts in the combustion process in a diesel engine, it consists of two namely the piston head and connecting rod, where the piston head consists of three parts, namely the piston crown, piston rings, and piston pins. This paper wants to prove which is more effective in modifying the TCC piston crown shape on a four-Stroke one-cylinder diesel engine fueled with B-30 in terms of noise. To measure noise, several experiments were carried out. One way is to use an application that can help make measurement easier is to use the simulation. The Simulation can measure the level of noise by using the tools in an application the same as in reality. The piston area is very influential on the combustion process, with the greater piston area, the resulting explosion is greater which results in and produces a high pressure also it is directly proportional to the noise level. After everything is measured, then we compare it with the engine's performance and give maximum results between the level of noise with engine performance. The result is using a piston case 4 (+1) which has a larger area experiencing the highest noise level using B30 Diesel Fuel or High-Speed Diesel (HSD) Fuel. Under load conditions, with a 50\% load, the noise level on piston +1 (Case 4) experiences the highest noise level using B30 Diesel Fuel or High-Speed Diesel (HSD) Fuel.
\end{abstract}

Keywords-noise, piston TCC.

\section{INTRODUCTION}

$\mathrm{T}$ echnology developments in the maritime industry currently show significant graphs and continue to improve renewable methods. Many modifications on the inside of the diesel motor can increase new ideas for a diesel engine going forward. One of the important things to look at is the piston set, which has a lot of variation. The shape of the piston is very affected in many aspects, such as the level of noise and vibration in the piston which will affect the performance of the diesel engine itself.

One of the main problems with diesel engines is the noise generated from the combustion process. Noise is an unwanted sound or sound that can interfere with the health and comfort of the environment expressed in disables $(\mathrm{dB})$. So that the noise from the combustion process that occurs should be in accordance with the specified limits namely existing international regulations from IMO, ILO, ISO 2923: 1996 [1].

Fuel in the engine serves to create combustion that can result in the expansion of power in the combustion chamber. Expansion of power in the combustion chamber will result in the piston being pushed from the top dead center (TDC) to the bottom dead center (BDC)

Beny Cahyono, Department of Marine Engineering, Institut Teknologi Sepuluh Nopember, Surabaya, 60111, Indonesia. E-mail: Benyjtsp98@gmail.com

Adhi Iswantoro, Department of Marine Engineering, Institut Teknologi Sepuluh Nopember, Surabaya, 60111, Indonesia. E-mail: adhi.iswantoro@gmail.com

Ilham Rezandhi Akbar, Department of Marine Engineering, Institut Teknologi Sepuluh Nopember, Surabaya, 60111, Indonesia. E-mail: ilhamakbarrezandhi@gmail.com
In choosing fuel, it must be adjusted to the characteristics of the engine. Here are some things to consider when choosing fuel [2].

Based on the high pass filtering technique, the noise and cylinder pressure signal is directly proportional to the noise itself [3].

Diesel engines have a high compression ratio because diesel engines have high pressure and temperature to burn diesel fuel completely. In addition, the quality of diesel fuel as seen from the cetane number affects the combustion process. By using a modified piston shape will be able to reduce and increase the level of noise.

The noise level limit has been made so that personnel is not exposed to Lex which exceeds $85 \mathrm{~dB}(\mathrm{~A})$. For new ships, compliance with this criterion must be verified based on sea level trials measuring noise levels by calculating expected noise exposure from each category of crew members by predetermined methods.

Because the piston under study is in the ship engine room, the maximum limit for noise levels in the engine room is $110 \mathrm{~dB}$ A) with a safe noise level of $85 \mathrm{~dB}(\mathrm{~A})$ [4].

Therefore, this paper research will examine the effect of standard piston crown shapes with modified on noise on Yanmar TF85 direct engine with biodiesel fuel B30.

Combustion is a process of a rapid chemical reaction between fuel fluid and air. This process produces an explosion in the combustion chamber. In an internal combustion engine, there are several combustion periods or stages for different engines.

In the Compression Ignition Engine, in the compression step, only the air has been compressed at very high pressure and temperature. The compression ratio used is in the range of 12 to 120 .

The temperature of the air becomes higher than the temperature of High-Speed Diesel (HSD) Fuel in the CI (Compression Ignition) engine. Then High-Speed Diesel 
(HSD) fuel is injected in the combustion chamber under very high pressure around 120 to 210 bar. Fuel temperature is around 20 to 35 degrees before Top Dead Point (TDC).

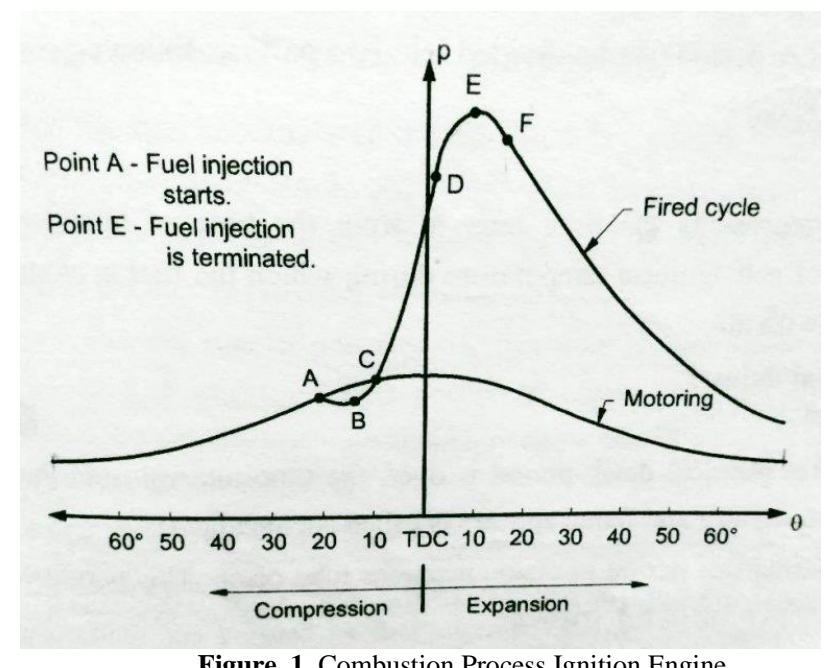

There are 4 different combustion stages as follows:

\section{Ignition Delay Period}

At this first stage of combustion in the CI engine, the fuel from the injection system is sprayed in the combustion chamber in the form of a jet. Due to atomization and vaporization, this fuel disintegrates at the core which is surrounded by a spray of air and fuel particles.

In this vaporization process, the fuel gets heat from the compressed and hot surrounding air. It causes some pressure drop in the cylinder. It can see at pressure drop (curve A-B) in the above figure

2. Period of Uncontrolled Combustion

This is the second stage of combustion in the CI engine. After the above-mentioned delay period is over, the air and fuel mixture will auto-ignite as they have achieved their self-ignition temperature.

The mixture of air and fuel in CI engines is heterogeneous unlike homogeneous in the SI engines. Due to this heterogeneous mixture, flames appear at more than one location where the concentration of the mixture is high.

During this stage, you can't control the amount of fuel burning, that's why this period is called a period of uncontrolled combustion. This period is represented by the curve $\mathrm{C}-\mathrm{D}$ in the above figure.

3. Period of Controlled Combustion

When the accumulated fuel during the delay period completely burned in the period of uncontrolled combustion, the temperature and pressure of the mixture in the cylinder are so high that new injected fuel from the nozzle will burn rapidly due to the presence of sufficient oxygen in the combustion chamber.

That's the reason we can control the rise of pressure into the cylinder by controlling the fuel injection rate.

Therefore, this period of combustion is called a period of controlled combustion.
4. After Burning

This is the last stage out of the four stages of combustion in a CI engine. Naturally, the combustion process is completed at the point when the maximum pressure is obtained in the combustion chamber at point $\mathrm{E}$ as shown in the figure.

Combustion of fuel in the combustion chamber continues during the expansion step. Although the fuel injection process has ended, the combustion process is still ongoing. If the continued combustion period is too long, it will cause the exhaust gas temperature to be high and will cause heat efficiency to decrease.

The diesel engine is a combustion engine using compression. The quality of the diesel fuel injected affects the combustion process occurring in the combustion chamber which will affect the pressure and temperature rise in the combustion chamber. Quality The diesel fuel used in diesel engines must have its own flammability or self-ignition when injected in compressed air. The lower the self-ignition point of diesel fuel will result in an increase in the combustion performance of a diesel engine which means an increase in the performance of a diesel engine. The quality of fuel in a diesel engine can be seen from the cetane number. The cetane number shows the ignition quality in the combustion chamber. The higher the cetane number the faster the ignition delay will reduce the possibility of knocking that affects vibration and noise. The average diesel engine requires fuel with a cetane number between 40-45. When using numbers that do not match the engine design will cause the following problems:

1. If it is too high, the effect of excessive heat on the engine can damage the engine components.

2. If it is too low, knocking symptoms arise due to incomplete combustion [5].

To produce good combustion. HSD fuel has the following conditions:

1. Flammable.

2. Not easy to experience freezing.

3. Has anti-knocking properties and makes the engine work softly. 
4. Has sufficient thickness to be sprayed into the engine by an injector.

5. Remain stable and do not experience changes in structure, shape, and color in the storage process.

6. Has a low sulfur content so as not to adversely affect the engine and reduce pollution.

Diesel engines or often called compression ignition engines. So, the combustion process that occurs in the engine cylinder occurs due to a mixture of compressed air with high temperature and pressure with diesel fuel. This mixing process causes a strong explosion, as the result of the explosion produces high noise and vibration.

The combustion process creates a force due to the rapid pressure of the rate of heat arising from combustion. Due to the proficiency level, the level of noise caused by the structure due to the large force acting on the motor will cause a beat or friction that causes and noise.

Increasing the speed of the engine will increase fuel requirements. This happens because increasing speed requires greater energy. Increasing the amount of fuel that enters the cylinder will increase ignition delay. The combustion process which has a long ignition delay causes the pressure in the cylinder to increase.

Fuel in the engine serves to create combustion that can result in an expansion of power in the combustion chamber. Expansion of power in the combustion chamber will result in the piston being pushed from the top dead center (TDC) to the bottom dead center (BDC) In choosing fuel, it must be adjusted to the characteristics of the engine. Here are some things to consider when choosing fuel [2].

1. Viscosity.

Viscosity is the level of viscosity of a fluid. Viscosity on the fuel will affect the ease of injection of the fuel. The smaller the viscosity value the fuel has, the easier it is for fuel to flow.

\section{Density.}

Density or what can be called specific gravity is defined by a comparison between weight and volume so that it has units of $\mathrm{kg} / \mathrm{m}$. Temperature change and the pressure experienced by the fuel can affect its specific gravity. The density value will increase if the temperature of the fuel decreases.

$3 . \quad$ Heating Value.

The heating value will affect fuel consumption. Where the higher the heating value, the less fuel is needed to get the same power.

4. Ignition Quality.

The quality of the ignition can be done by modifying the injection time of the fuel, the temperature in the combustion chamber, the temperature of the fuel, and the opening and closing time of the valve mechanism. Ignition quality will affect the engine performance and emission levels that will be generated.
5. Carbon residue.

Fuels with high carbon content can have an impact on the amount of deposition resulting from combustion.

6. Sediment and Ash Content.

Solid particles such as ash can cause wear on some engine components, for example in fuel injection pumps, injectors, cylinder liners, piston rings, valve systems, and even can accelerate component wear on turbocharger systems. To reduce sediment and ash content, one of them is by purifying fuel.

$7 . \quad$ Sulfur Content.

Sulfur content is one of the dangerous ingredients in fuel. That is because sulfur is acidic which can cause corrosion to engine components.

8. Flash Point.

The flashpoint is the lowest temperature when it can evaporate to form a liquid that can ignite the fire in the air. the flashpoint on diesel fuel is influenced by the value of cetane contained.

9. Pour Point.

Pour point is the temperature of the fuel that can be poured after experiencing freezing.

\section{RESEARCH METHODOLOGY}

The stages of the method of conducting research are used, the stages of the research can be seen as follows:

\section{A.Calibration with Engine Simulation}

At this stage, before we modify the piston and check the noise and vibration levels of the engine, we first calibrate the Yanmar TF85 engine, which is needed before performing the calibration as follows:

a) Properties Fuel Diesel Engine.

b) Catalog Yanmar TF85 Diesel Engine.

c) Modified Piston Yanmar TF85.

d) Level of Noise placement simulation.

Determination of the variables used are as follows:

a) RPM 1600, 1700,1800,1900,2000,2100,2200.

b) Palm Oil Diesel Fuel Engine.

c) Level of Noise 1 meters Infront of engine with Load 50\%, 60\%, 70\%, 75\%, 80\%, 90\%, and $100 \%$.

d) Comparison of piston standard and modified piston.

\section{B. Simulation Diesel Engine}

Data collection is carried out repeatedly with several variations of RPM, piston modification, variation loads, with two types of diesel fuel as support to analyze the results level of noise. Data is done by running software. 


\begin{tabular}{ccccc}
\hline Parameters & Units & HSD & B30 & Analysis Methods \\
\hline Density $15^{\circ} \mathrm{C}$ & $\mathrm{Kg} / \mathrm{L}$ & 815 & 844,4 & Piknometri \\
Viscosity $40^{\circ} \mathrm{C}$ & $\mathrm{mm} 2 / \mathrm{s}$ & 2 & 2,2 & Viskometri \\
LHV & $\mathrm{kal} / \mathrm{g}$ & 10330.09 & 10533.9 & Bomb calorimetri \\
Flash Point & ${ }^{\circ} \mathrm{C}$ & 52 & 91 & ASTM D-93 \\
Cetana & - & 48 & 73,2 & Octane-cetane Analizer \\
Number & - & & & \\
\hline
\end{tabular}

C. Modified Piston

The modified piston used in this simulation is a TCC
(Toroidal Combustion Chamber) piston with several variations of modifications on the piston crown.

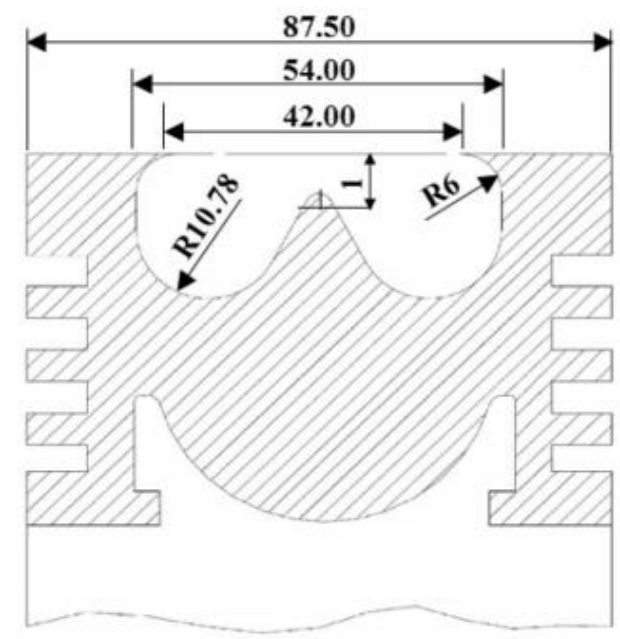

Figure. 2.

Piston TCC Side View

For the shape of the piston crown to be modified, it is the TCC (Toroidal Combustion Chamber) piston crown, necessary to assume a table of changes in the shape of as follows:

\begin{tabular}{lllllr}
\multicolumn{7}{c}{ TABLE. 2 } \\
PISTON SIZE \\
\hline $\begin{array}{l}\text { Type } \\
\text { Piston }\end{array}$ & $\begin{array}{l}\text { Bowl } \\
\text { Depth } \\
(\mathbf{m m})\end{array}$ & $\begin{array}{l}\text { Bowl } \\
\text { Diameter } \\
(\mathbf{m m})\end{array}$ & $\begin{array}{l}\text { TDC } \\
\text { Clearance } \\
(\mathbf{m m})\end{array}$ & CR & \multicolumn{2}{l}{$\begin{array}{l}\text { Connecting } \\
\text { Rod }\end{array}$} \\
\hline Case 1 & 15,5 & 45 & 0,8 & 18 & 118.1 \\
Case 3 & 14,5 & 45 & 1,08 & 18,01 & 117.82 \\
Case 4 & 16,5 & 43,4 & 0,7 & 17,97 & 118.2 \\
\hline
\end{tabular}

This is a 2D picture design type of piston standard, $\quad$ piston -1 , and piston +1 :
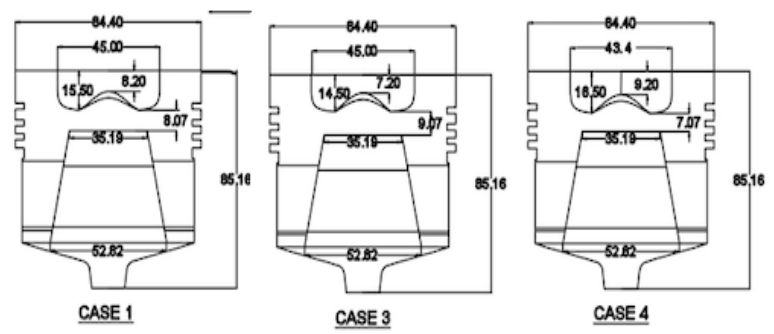

Figure. 3. Piston Standard, Piston -1 , and Piston +1

D. Noise Point Measurement certain time interval, usually less than 30 seconds [6].

Basically, it is a weighted average of time over a 


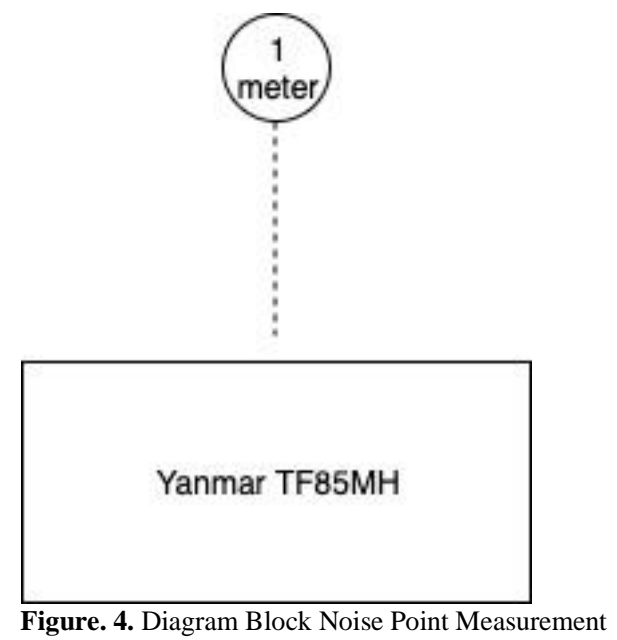

The 'source' noise level must be measured at a predetermined distance from the unit [usually $1 \mathrm{~m}(3.3$ $\mathrm{ft}$ )] and is used to characterize the air source needed for acoustic modeling. It is generally best to determine these levels in the octave band so that they can be used as input data for detailed noise analysis [6].
By using the software, glue the parts to the noise by giving the components that are attached to the engine that is the microphone with the placement as shown below:

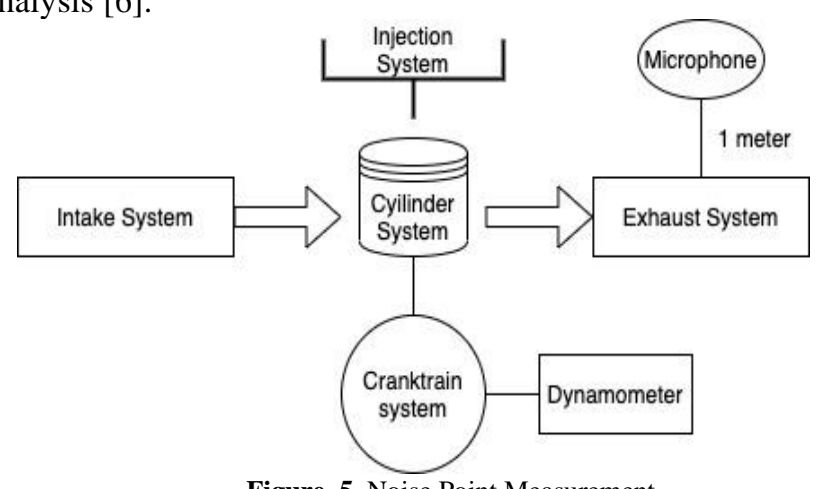

Figure. 5. Noise Point Measurement

After that, measurements are made per meter according to the existing rules of 1 meter in front of the engine itself with RPM 1600, 1700, 1800, 1900, 2000, 2100, and 2200 with load 50\%, 60\%, 70\%, 75\%, 80\%, 90\%, 100\%, and Full Load.

\section{RESULT AND DISCUSSION}

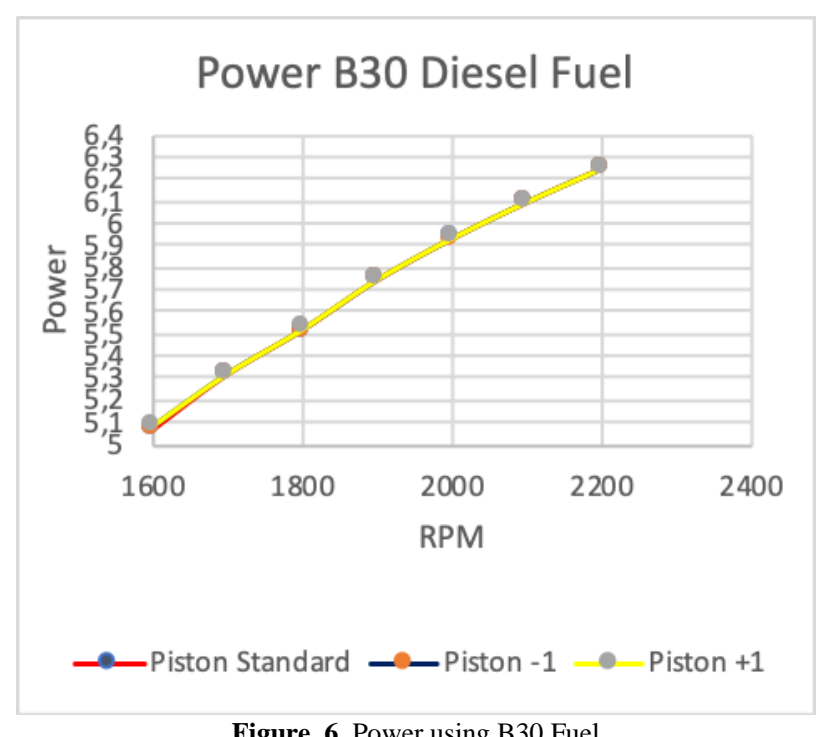

Figure. 6. Power using B30 Fuel

In the Graph can see the comparison of the power generated from 3 different types of pistons, namely
Standard Piston, Piston -1 , and Piston +1 . The power produced from 3 types of pistons shows the difference in 
power produced by the engine. Where the highest RPM is RPM 2200, Piston +1 has a power of $6,251 \mathrm{~kW}$, a Standard Piston has a power of 6,250 kW, and a Piston 1 has a power of $6,247 \mathrm{~kW}$. When the engine RPM rises, the engine power output also increases.

This is proportional to the pressure and the explosion of combustion in the combustion chamber is increasingly high. The conclusion is that Piston +1 has a higher power in each engine RPM, followed by a Standard Piston, then finally Piston -1 has the lowest power in each RPM.

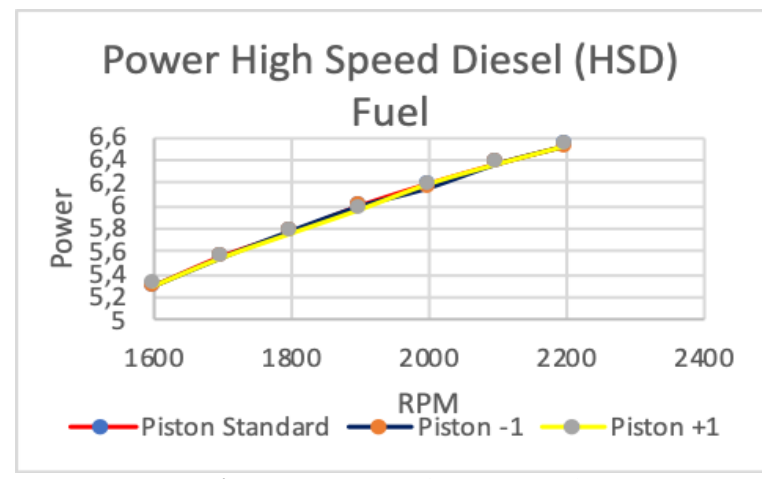

Figure. 7. Power using HSD Fuel

From the Graph, we can see the comparison of the power produced from 3 different pistons, namely Standard Piston, and Piston -1 , and Piston +1 . The power produced from 3 types of pistons shows the difference in power produced by the engine. Where the highest RPM is RPM 2200, Piston +1 has a power of $6,523 \mathrm{~kW}$, Piston Standard has a power of $6,522 \mathrm{~kW}$, and Piston -1 has a power of $6,528 \mathrm{~kW}$. When the engine RPM rises, the engine power output also increases.
This is proportional to the pressure and the explosion of combustion in the combustion chamber is increasingly high. The conclusion is that Piston +1 has a higher power in each engine RPM, followed by a Standard Piston, then finally Piston -1 has the lowest power in each RPM.

\section{A. Noise}

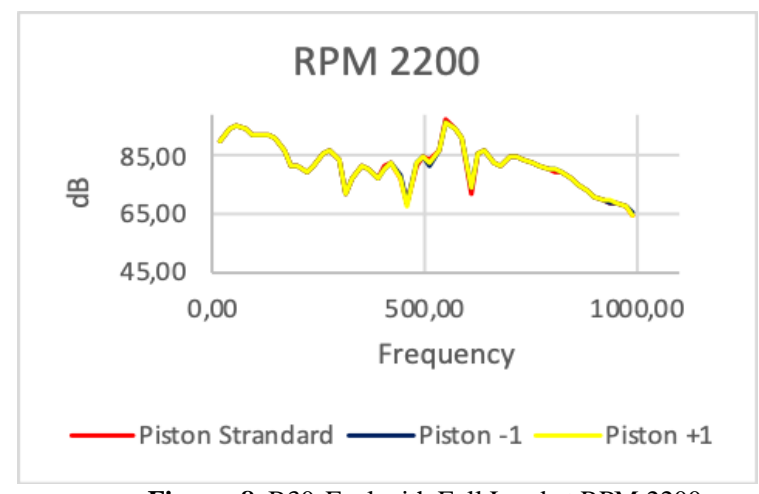

Figure. 8. B30 Fuel with Full Load at RPM 2200

In the Graph of Sound Pressure B30 Diesel Fuel RPM 2200 Full Load with All Variant Piston, it can be seen the comparison of the noise level at 2200 RPM Full Load conditions with 3 variations piston of the B30 diesel fuel. The highest noise level occurs at a frequency of $55 \mathrm{~Hz}$ with +1 Piston of $96.18 \mathrm{~dB}$, followed by a
Standard Piston of $96.18 \mathrm{~dB}$, and the last Piston -1 of $96.17 \mathrm{~dB}$. Piston +1 has the highest noise level because it has a higher power compared to the standard piston and 1.

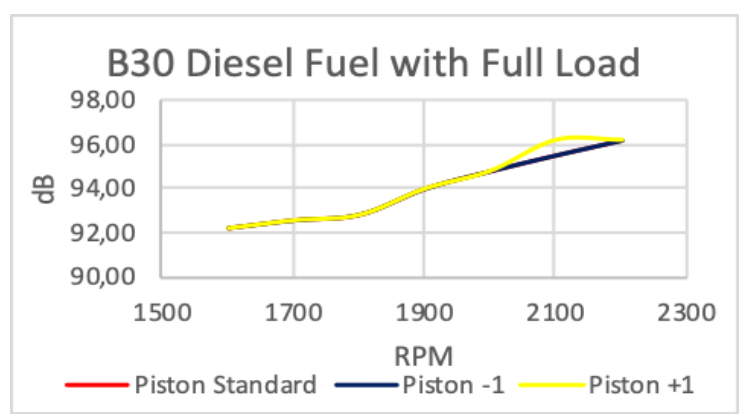

Figure. 9. B30 Full Load Condition 
In the graph B30 Diesel Fuel with Full Load, it can be seen the comparison of the noise level to RPM with B30 diesel fuel. Piston +1 has a higher noise compared to Standard piston and Piston -1. Can be seen the increase in engine rotation speed has an impact on the increase in the level of noise produced by the engine.
That is caused by the increase in engine rotation speed, the pressure in the combustion chamber increases, and the power produced by the engine is greater, this has an impact on the sound or noise produced by the engine itself.

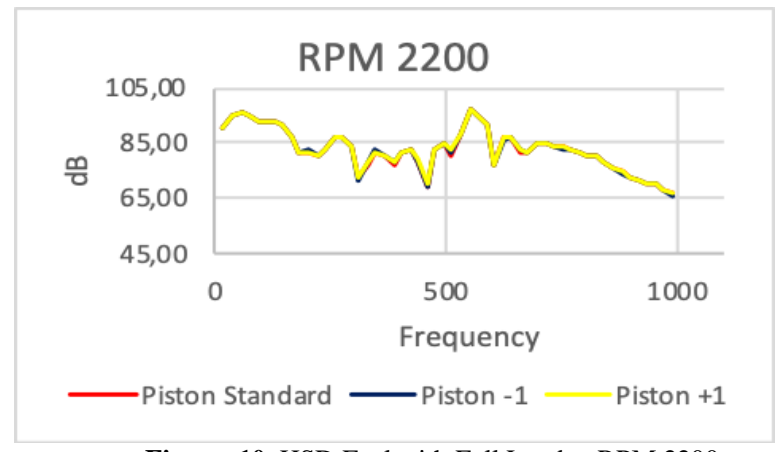

Figure. 10. HSD Fuel with Full Load at RPM 2200

In the Graph of Sound Pressure High-Speed Diesel (HSD) Fuel RPM 2200 Full Load with All Variant Piston, it can be seen the comparison of the noise level at 2200 RPM Full Load conditions with 3 variations piston of the High-Speed Diesel (HSD) Fuel. The highest noise level occurs at a frequency of $55 \mathrm{~Hz}$ with +1 Piston of
$96.47 \mathrm{~dB}$, followed by a Standard Piston of $96.46 \mathrm{~dB}$, and finally at Piston -1 of $96.45 \mathrm{~dB}$. Piston +1 has the highest noise level because it has a higher power compared to the standard piston and -1 .

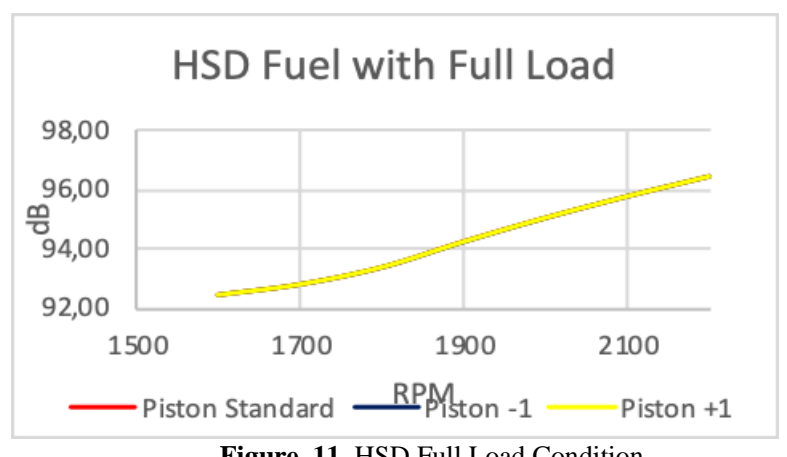

Figure. 11. HSD Full Load Condition

In the graph High-Speed Diesel (HSD) Fuel with Full Load can be seen the comparison of the noise level to RPM with High-Speed Diesel (HSD) Fuel. Piston +1 has a higher noise compared to Standard piston and Piston 1. Can be seen the increase in engine rotation speed has an impact on the increase in the level of noise produced by the engine. That is caused by the increase in engine rotation speed, the pressure in the combustion chamber increases, and the power produced by the engine is greater, this has an impact on the sound or noise produced by the engine itself.

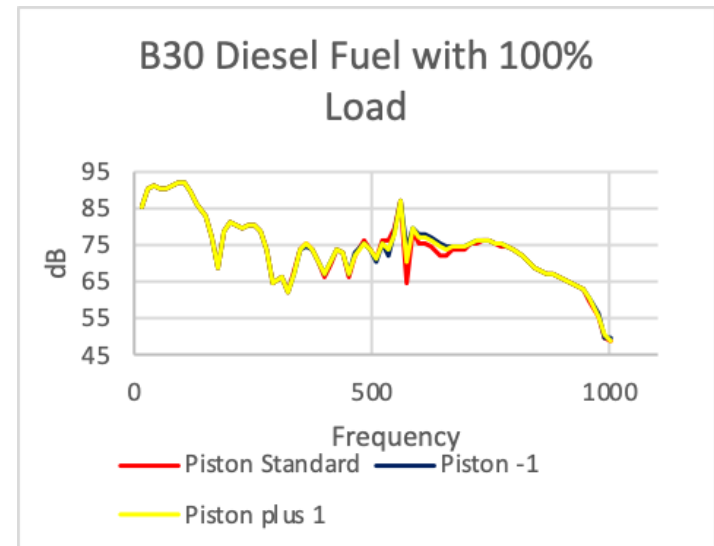

Figure. 12. RPM 220 with $100 \%$ load with B30 Fuel 
In the graph B30 Diesel Fuel with $100 \%$ Load, it can be seen comparing the noise level at 2200 RPM $100 \%$ Load condition B30 diesel fuel. Noise on Piston +1 is higher compared to standard Piston and Piston -1. At a frequency of $93.3 \mathrm{~Hz}$, the +1 piston has a noise of 92.27 dB. For Piston Standard at $93.3 \mathrm{~Hz}$ frequency has a noise of $92.26 \mathrm{~dB}$ and Piston -1 at $93.3 \mathrm{~Hz}$ frequency has a noise of $92.25 \mathrm{~dB}$. Piston +1 has a higher noise level than the standard piston and piston -1 because it has a higher power compared to the standard piston and piston-1.

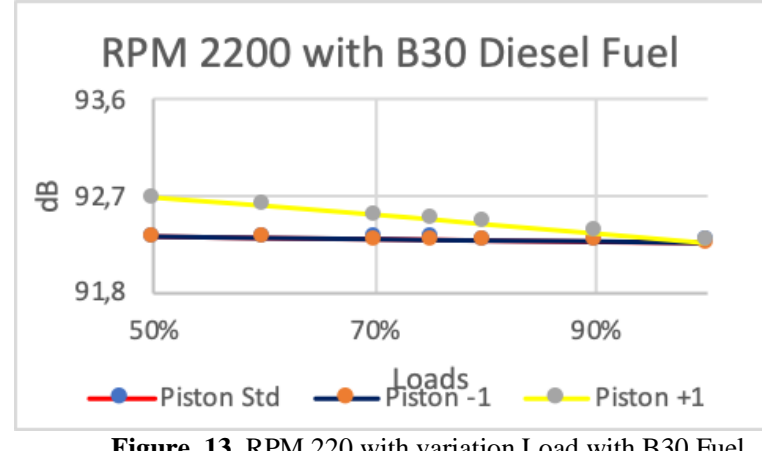

The graph RPM 2200 with B30 Diesel Fuel, shows the comparison of the noise level at 2200 RPM using variations load using B30 diesel fuel. Can be seen the level of engine noise that uses type piston +1 , piston standard, and piston -1 tends to fall, although the noise level is different the graph still shows a decrease when given load. Piston +1 has a significant reduction while the standard piston and piston -1 are not too significant.

Piston +1 has the highest noise point of $92,68 \mathrm{~dB}$ with a minimum point of $92,27 \mathrm{~dB}$, followed by a Standard Piston with a maximum point noise of $92.32 \mathrm{~dB}$ and a minimum point of $92,26 \mathrm{~dB}$, then Piston -1 with a maximum point of $92,31 \mathrm{~dB}$ and the minimum point of noise $92,25 \mathrm{~dB}$. It can be seen that piston -1 is the piston that has the lowest noise level compared to standard piston +1 and piston standard.

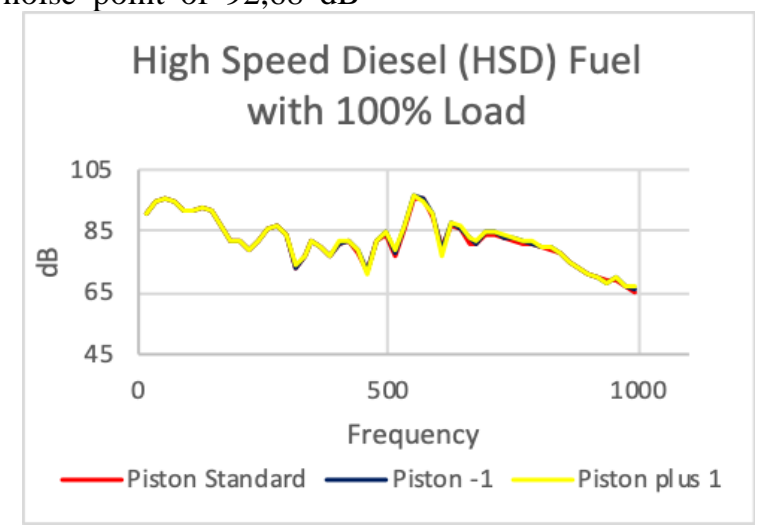

Figure. 14. RPM 220 with $100 \%$ load with HSD Fuel

In the graph High-Speed Diesel (HSD) Fuel with $100 \%$ Load, it can be seen comparing the noise level at 2200 RPM 100\% Load condition High-Speed Diesel (HSD) Fuel. Noise on Piston +1 is higher compared to standard Piston and Piston -1. At a frequency of $54.9 \mathrm{~Hz}$, the Piston +1 has a noise of $96.11 \mathrm{~dB}$. For standard pistons, at a frequency of $54.9 \mathrm{~Hz}$, it has a noise of 96.09 $\mathrm{dB}$ and a Piston -1 at a frequency of $54.9 \mathrm{~Hz}$ also has a noise of $96.09 \mathrm{~dB}$. Piston +1 has a higher noise level than the standard piston and piston -1 because it has a higher power compared to the standard piston and piston-1.

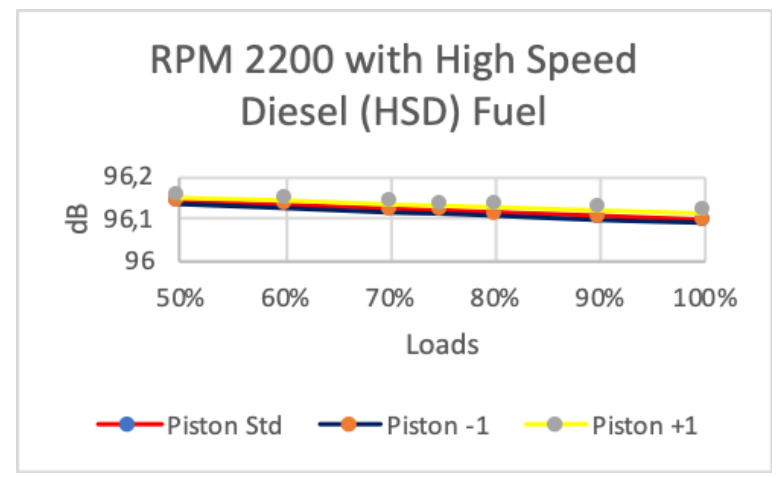


Figure. 15. RPM 220 with variation Load with HSD Fuel

The graph RPM 2200 with High-Speed Diesel (HSD) Fuel, shows the comparison of the noise level at 2200 RPM using variations load using HSD fuel. Can be seen the level of engine noise that uses type piston +1 , piston standard, and piston -1 tends to fall, although the noise level is different the graph still shows a decrease when given load.

Piston +1 has the highest noise point of $96.15 \mathrm{~dB}$ with a minimum point of $96,11 \mathrm{~dB}$, followed by a Standard Piston and Piston -1 of $96,14 \mathrm{~dB}$ with a minimum point of $96,09 \mathrm{~dB}$. It can be seen that piston -1 is the piston that has the lowest noise level compared to piston +1 and piston standard.

From the results of the analysis, piston +1 which is the result of piston modification in this paper, is a piston with noise and vibration levels of the highest good in B30 diesel fuel and diesel fuel.

Because the piston +1 has a greater area compared to other pistons and also has greater power. A power that is largely due to the combustion process generates a large explosion and resulting pressure experienced engine noise and vibration levels are higher.

The noise level is greatly affected by rotation. With increasing rotation, the engine has increased work. An increase in work will increase the amount of fuel that enters the cylinder. Increasing the amount of fuel that enters the cylinder will require greater pressure to ignite.

\section{CONCLUSION}

Based on the simulation results and data obtained during the study, there is some conclusion that the author would summarize:

1. The highest noise level occurs in piston +1 (Case 4) with B30 Diesel Fuel or High-Speed Diesel (HSD) Fuel. The lowest noise level occurs in piston -1(Case 3) with B30 Diesel Fuel or High-Speed Diesel (HSD) Fuel. The effect of load on RPM 2200 B30 fuel with the highest noise level occurs at $50 \%$ load with piston +1 with 92.68 $\mathrm{dB}$ noise level, while the lowest noise level occurs at $100 \%$ load with piston -1 with $92,25 \mathrm{~dB}$ noise level. Effect of load on RPM 2200 HSD fuel with the highest noise level occurs at $50 \%$ load with piston +1 with 96,15 $\mathrm{dB}$ noise level, while the lowest noise level occurs at $100 \%$ load with piston -1 with noise level 96,09 dB. So, the piston modified -1 (Case 3) has a lower noise level rather than piston standard Yanmar TF85 and piston modified +1 (Case 4$)$.

\section{ACKNOWLEDGMENT}

The author would like to praise and thanks Allah SWT for giving the knowledge, strength, and wisdom in order to complete these studies. In expectation, the result of this paper would be a beneficial aspect both for the author's knowledge and surroundings that are involved in this aspect. The author would give the warmest regards and appreciation For Lab Marine Power Plant, Department of Marine Engineering, Faculty of Marine Technology, Sepuluh Nopember Institute of Technology
Surabaya, who had helped and contributed highly by guiding and providing knowledge in the completion of this bachelor paper.

\section{REFERENCES}

[1] Annur, M. N., 2019. PENGARUH PEMANASAN BAHAN BAKAR B20 DAN B30 TERHADAP NOISE MESIN DIESEL SINGLE SILINDER.

[2] Harrington, R. L., 1992. Marine Engineering. s.l.:s.n.

[3] Narayan, S., 2015. CORRELATION BETWEEN CYLINDER PRESSURE AND NOISE EMISSIONS FROM DIESEL ENGINES. Journal of KONES Powertrain and Transport, Vol. 22, No. 12015.

[4] SOLAS, 2012. SOLAS Regulation II-1/3-12. 30 November 2012 ed. s.1.:s.n.

[5] Coppenberg, A. D., 2017. Pengaruh Pengunaan Bahan Bakar Solar, Biosolar. Jurnal Konversi Energi dan Manufaktur UNJ.

[6] Shipping, A. B., 2017. ABS GUIDANCE NOTES ON NOISE AND VIBRATION CONTROL FOR INHABITED SPACES . 2017. s.1.:s.n.

[7] Hidup, m. N. L., 1996. Keputusan Menteri Negara Lingkungan Hidup No. 49 Tahun 1996 Tentang : Baku Tingkat Getaran. s.1.:s.n.

[8] PRABHAKARA RAO GANJI, R. N. S. V. R. K. R. S. S. R., 2018. Design of piston bowl geometry for better combustion in direct-injection compression ignition engine. Sådhanå (2018) 43:9 